in the botanical exploration of the Kentani district, and to whom are dedicated the two new species of Mystacidium figured-her own discoveries. To these and others Dr. Bolus gives grateful recognition in his introductory note.

An index comprising a list of species and synonyms is placed at the end of the text matter, and a good portrait of the author as a frontispiece is a pleasing addition.

A. B. R.

THE STUDY OF FIELD CROPS.

Southern Field Crops (exclusive of Forage Plants). By Prof. J. F. Duggar. Pp xxvii +579. Rural Textbook Series; edited by L. H. Bailey. (New York: The Macmillan Co.; London: Macmillan and Co., Ltd., IgII.) Price $7 s$. $6 d$. net.

A $\mathrm{T}$ a certain stage in his studies the agricultural A student is called upon to consider crop-growing in its economic aspects, and he soon finds himself in a wide and rather indefinite field, where, in theory, his chemistry, botany, entomology, \&c., ought to meet, and where the bearing of all the sciences on practical agriculture ought to be made manifest. In theory the student is to be directed in his studies of this branch of the subject by a man whose attainments in these several sciences is beyond reproach, and who has also a first-hand acquaintance with the economic problems involved. But in practice this ideal combination is never attained, and consequently the study of field crops goes in with agriculture, and is left entirely to the empiricist, no man of science having set up any claim to deal with them from the economic point of view.

Like other teachers of agriculture, Mr. Duggar is an empiricist; but he is an enlightened one, and makes liberal use of the data accumulated by his confrères on the science side. He deals, as one would expect, very fully with maize and cotton, to each of which some ten chapters are devoted, the rest of the book being occupied with the less common crops-wheat, oats, sorghum, rice, \&c. The usual arrangement of the subject-matter is to begin with the structure of the plant; then to pass on to its races and varieties, the methods of breeding or improvement, the soils and fertilisers best adapted, the appropriate tillage and cultivation, and finally the insect and fungoid pests. Thus the whole field of science is covered, from chemistry and botany to entomology.

Considering how much such a task is beyond the powers of any one man, Mr. Duggar has done remarkably well. The purist in method, of course, might object to the empirical treatment of the subject, and feel dissatisfied with the numerous bald statements, such as "Insect pests [of oats] are the same as those of wheat, except that the oat is not attacked by the Hessian fly," just as the purist in language (and many others as well) might object to another statement"ensilage is the verb, as 'to ensilage corn,' with the accent on the middle syllable." But these difficulties are inherent in the subject, and it would be unreasonable to judge the book from a point of view other than that from which it was written and will probably be used.

NO. 2I02, VOL. 88 !
For in the meantime, while he is waiting for the true scientific treatment of crop husbandry to be developed, the student needs some one book in which he can find collected all the information he wants about ordinary crops. He is more concerned with the facts themselves than with their bearing on one another or on any central hypothesis. From this point of view Mr. Duggar's book is very good; there has obviously been a great deal of work expended in collecting the facts, and the references to the literature at the end of each chapter, if not entirely satisfying to the man of science, will at any rate put the student in touch with other work on the subject. In the present state of our knowledge the collection of the facts relating to the growth of crops is extremely necessary for further progress, and Mr. Duggar has contributed material that will be found distinctly useful.

As in the other members of this series, the book is well illustrated, and the pictures are well chosen, there being remarkably few of the ordinary useless field views. "An honest book," Dr. Bailey calls it in his introduction; ". . . these makers of observation textbooks, that present the crops and the animals in their real and living details, will set going a great quiet movement to examine minutely the conditions of agricultural failure and success." $\quad$ E. J. Russell.

\section{PROPERTIES OF MATTER.}

General Physics for Students: a Text-book on the Fundamental Properties of Matter. By E. Edser. Pp. ix +632 . (London: Macmillan and Co., Ltd., I9rr.) Price $7 s .6 d$.

$\mathrm{T} \mathrm{T}$ is not often that a text-book, published under a familar title, presents so many novel and valuable features as Mr. Edser's latest production, "General Physics for Students." It is scarcely too much to say that with regard to contents and general mode of treatment the book forms a class for itself. By the collection of so much fresh material into one volume, Mr. Edser has made accessible to students many parts of physics, which, either from lack of time or initiative, they have hitherto been unable to appreciate. This has been done in no meagre fashion, the details, both experimental and theoretical, being consistently of a very comprehensive character.

The very care which has obviously been bestowed upon the work in order to suit it to the needs of students has, we think, been the cause of the one unfortunate feature of the book. This is the avoidance of the use of calculus notation-a procedure which the author seeks to justify in the preface. There is undoubtedly much to be said for such omission in the case of junior students whose teaching involves but rare recourse to calculus methods; but to continue the practice through a book of this kind is open to grave objections. The students who use the book may be divided into two classes-those sufficiently acquainted with calculus notation and methods, and those ignorant of them. The former class are liable to become annoyed at the repeated integration from first principles of the same function; the latter class may become accustomed to regard the laborious processes given as essential parts of the problems in 